\title{
Book Review: Why Music Matters by David Hesmondhalgh
}

\author{
LI ZHONGWEI, London School of Economics and Political Science
}

Hesmondhalgh, David (2013) Why Music Matters, Malden: Wiley-Blackwell, ISBN: 978-1-4051-9242-2 (hardcover); 978-1-4051-9241-5 (paperback); 978-1-118-53581-3 (e-book), 198 pages.

Why music matters? Music researchers (including me) too often neglect to ask themselves this question, and when some do ask, they tend to take the answer for granted. Posing this question as the title of his latest book, David Hesmondhalgh aims to offer a 'critical defense of music' (3). Such a defense is needed, Hesmondhalgh argues, because the value of music as a form of art and cultural activity is recently under two kinds of attack. One comes from neo-liberalist 'economic conceptions' (3) of human life which have led to devaluation of music and art in policymaking. The other comes from the academia, where traditional ways of defending aesthetic values have also been fundamentally challenged. As sociologists like Pierre Bourdieu have powerfully shown, discusses Hesmondhalgh, rather than a transcendent and autonomous realm, art is a myth constructed and deeply intertwined with relations of social power, and a new theoretical basis for the value of artistic practices is yet to be formed. This is the gap which Hesmondhalgh aims to fill with his book. The monograph's objective, therefore, is not just to show that music matters, but also to demonstrate that music matters in perhaps more comprehensive but subtle ways than we tend to think.

Hesmondhalgh's book accomplishes both tasks. It makes a strong defense of the value of music against the new utilitarianism in government; it is also a refreshing, multi-layered presentation of music's transformative capacities. The key to Hesmondhalgh's endeavor is a sophisticated conception of the roles of music in modern societies, which is both interdisciplinary and dialectical. In Hesmondhalgh's analysis, music is seen as having two 'contrasting yet complementary dimensions' (1) in relation to our lives: on the one hand, drawing from the affective turn in anthropology, musicology, and aesthetics, Hesmondhalgh stresses music's distinctive capacity of transforming our personal emotions and feelings; on the other hand, he also recognizes the pivotal role of music as 'the basis of collective, public experience' (2) which is manifested in the work of a generation of sociologists and media scholars. More importantly, the private and the public are regarded 
here not as a dichotomy but as a spectrum, and their connection is to be found in the function of music as the 'remarkable meeting point of intimate and social realms' (2).

This conception of music is the very thread linking all chapters together. Hesmondhalgh's monograph steadily shifts its focus from the private self towards wider public realms. Chapter 2 investigates the contribution of music to our lives at the individual level, in particular through its capacity to engender feelings and emotions. After an examination of various approaches to music and affect, Hesmondhalgh builds his own perspective on Martha Nussbaum's Aristotelian notion of human flourishing which provides an 'objectivist and pluralist' (20) understanding of both music's unique relation to emotion and its link to the critical issue of social justice. As a supplement, Hesmondhalgh enriches Nussbaum's high-culture-oriented approach with accounts of the bodily experience of music through dancing and the ordinary experience of music in everyday life. Then, Chapter 3 moves the discussion into the realm of people's intimate relations and explores the historical role of popular music in 'enhancing human experiences of love and sex' (58). The chapter offers a roughly chronological and genre-based examination of how different musical styles (countercultural rock, post-war pop, dance music etc.) draw upon affective experiences of sexuality and intimacy.

The last two chapters go beyond the level of individual flourishing and ask 'how might we flourish together' (84). Chapter 4 analyzes co-present musical participation as a form of space-based publicness and extends it to the thesis of locality. Looking back on celebrations of musical participation by Christopher Small, Charles Keil, and Thomas Turino, Hesmondhalgh points out that the ideal notion of community held by those theorists is 'not feasible in conditions of modernity' (88). He instead tries to theorize the ordinary ways - for example, singing, dancing, or making music together - in which positive musical sociality can be found under the 'dialectic of individualization and collectivity in modern societies' (88). The final, fifth chapter turns its focus from co-present sociability to mediated commonality, that is, to music's potential of 'transcending or containing social difference' (130) across different communities and places. Assessing theoretical attempts to redeem the 'emancipatory dimension of aesthetics' (133) which are often centered on the value of aesthetic deliberation, Hesmondhalgh follows Jeff Weintraub to draw a distinction between the deliberative forms of publicness which are grounded in citizenship and oriented towards collective political action, and the sociable forms of publicness which are based on the 'shared experience, attachment, and solidarity towards other human beings' (87). Hesmondhalgh argues that music makes a much stronger contribution to a better world through the latter than through the former type of publicness - in other words, the most significant effects of music on collective flourishing are 'not directly political' (10) as in the cases of famous protest songs or campaign songs, but via music's mundane capacity of drawing people together. This brave conception of music's relation to politics is presented through case studies on different forms of musical collectivities. In particular, Hesmondhalgh discusses music's ambivalent relation to nationalism and cosmopolitanism with a wealth of cases on the production and consumption of music across space and time. 
For Hesmondhalgh, one of the important lessons learned from past theorizations of artistic value is that one should always resist the temptation to construct 'music' into a transcendent ideal. The highest merit of his book lies in its calm narrative and critical orientation towards the real condition of our existence. Hesmondhalgh's critical defense of the value of music is never a mere celebration: as he points out, just as important as the ways in which music can enrich our lives are the 'social and psycho-social factors' that might severely constrain music from doing so (6). His analysis is thus deeply rooted in the everyday experiences of the 'plain old modern life' (101), and on a critical awareness of the social and institutional barriers which restrict both the conditions of music production and the forms of human commonality. Therefore, it is the ambivalence of the role of music under capitalist modernity that is a central concern for Hesmondhalgh. For example, in Chapter 2, right after demonstrating the positive capacity of music as a 'resource for forging self-identity' (48), Hesmondhalgh does not hesitate to reveal the dark side of the same power, arguing that 'the use of music for self-management can be bound up with the competitive individualism that is prevalent throughout modern societies' (48). Similarly, in Chapters 4 and 5, 'collectivity' is examined as a dialectical term which bears the potential to enhance solidarity and equality as well as the danger of narrowing down the opportunities to flourish in the lives of others (85). As a result, in the book we see not only the beneficial contributions of music to self-realization and collective flourishing, but also its equally significant relations to modern problems such as individualistic narcissism, social exclusion, and conservative nationalism.

With all its critical value, however, Hesmondhalgh's book leaves undeveloped a crucial point fundamentally linked to the complex roles of music in modern society: the nuances of music itself and its materiality. In Chapter 2, we see the case of an enthusiastic music collector Paul who acknowledges that his desire to 'accrue amounts of music that he could not possibly play more than once or twice' (46) was irrational. Paul's case is used as an example of 'people who seem to place a particularly strong emphasis on self-realization through musical consumption'. While Hesmondhalgh is right to point out the 'atypicality' (46) of the case, his analysis does not go deeply enough to fully reveal the underlying problem. Seen under a micro-sociological perspective which highlights the affective capacities of music, Paul's irrational behavior of collecting records is driven by 'the quest for personal authenticity through music' which 'had become so important that it almost seemed to fill his house' (47). However, such an analytic emphasis misses the central issue which is not about the degree of music's impact on identity, but the forms music takes in doing so. In other words, the assumption that the CDs and records purchased are the very music they contain should not be easily taken for granted. Music, which may be defined as the organized sound sung by voices or played through instruments, is certainly not equal to the medium of storage which enables people to retrieve its sound in the recorded form. Thus what underlies the question why music matters is another more basic one, namely what music is; in other words, what are we referring to when we talk about 'music' in the modern context? Has our relation to music been so much mediated by increasingly commercialized materials that in the end its real essence, the organized sound, no longer 
matters? Or in the words of Will Straw (2002, 147): 'in what ways does the physical form of cultural commodities shape their circulation, or the nature and extent of their influence?'

Of course, this point is right in line with Hesmondhalgh's critical project, in that the question of materiality relates directly to the question of ownership, and ultimately leads to that of modern individualism. If music is defined as the organized sounds being made, one might argue that music only exists in the constant flow of time in our experience of playing or listening, or as Alfred Schutz $(1951,92)$ puts it, in the 'mutual tuning-in relationship' between players and listeners. In this sense, music is simply not something that can be owned but only something to be shared. It follows that collecting music by owning its storage media - whether material or digital - is a completely modern form of our interaction with music. Thus, Paul's case might be more appropriately examined under Baudrillard's $(1994,12)$ argument that 'it is invariably oneself that one collects', which echoes the link Hesmondhalgh draws between music and individualistic narcissism in Chapter 3 and his discussion on the replacement of the amateur and the listener by the 'compliant consumer' (114) in Chapter 4. While the transformative capacities of music are not necessarily associated with its medium, there certainly exist different ways in which the latter can significantly alter or constrain music's contribution to human flourishing. These mechanisms have become increasingly relevant along with the development of neo-liberal cultural industries, yet they remain implicit in Hesmondhalgh's account which applies a single and simple label 'music' to a more complex set of processes including production, consumption, and mediation under capitalist modernity. Therefore, in discussing why music matters, it would be helpful to draw clearer distinctions between the 'music' in question, between the various forms or media it takes, and between their dynamic interactions. Such distinctions could aid further critical reconsideration of the relationship of music with history, society, and subjectivity.

All in all, this concise book unfolds Hesmondhalgh's critical engagement with a wide range of academic traditions through vivid case studies across different genres in music history and is a delightful reading experience. The monograph will be insightful for novice researchers looking for a clear concept map of their field as well as professional music scholars who seek a breakthrough from their disciplinary conventions.

\section{References}

Baudrillard, J. (1994) 'The System of Collecting'. in J. Elsner and R. Cardinal (eds), The Cultures of Collecting, London: Reaktion Books, pp. 7-24.

Schutz, A. (1951) 'Making Music Together: a Study in Social Relationship', Social Research, 18, 76-97. 
Straw, W. (2002) 'Music as Commodity and Material Culture'. Repercussions, 7-8 (Spring-Fall, 1999-2000), 147-172.

Li Zhongwei is a PhD researcher in Media and Communications at the London School of Economics and Political Science. His research focuses on the 'Cut-out Generation' in China, who are the first Chinese generation of Western rock music audiences in the 1990s, and his thesis explores the relationship between music consumption, cultural identity, and social resistance in this case. He holds an MPhil in Sociology from the University of Cambridge and a BA in Education from Beijing Normal University.

Email: Z.Li44@1se.ac.uk 